\title{
e.Xactal \\ Medidas Sustentáveis no Mercado de Café em Dose ÚNICA
}

ISSN: 1984-3151

\author{
Sustainable Measures in Single-Serve Coffee Market
}

\author{
1 Doutorando em Administração. Universidade \\ Federal de Lavras - UFLA, 2017. Lavras, MG. \\ educesar muz@hotmail.com. \\ 2 Mestranda em Administração. Universidade \\ Federal de Lavras - UFLA, 2017. Lavras, MG. \\ angelica.soad@gmail.com. \\ 3 Doutor em Economia Aplicada. Universidade de \\ São Paulo - USP, 1999. Professor do \\ Departamento de Administração e Economia da \\ UFLA. Lavras, MG. gonzaga.ufla@gmail.com.
}

Eduardo Cesar Silva1; Angélica da Silva Azevedo²; Luiz Gonzaga de Castro Junior ${ }^{3}$

Recebido em: 27/01/2017 - Aprovado em: 29/08/2017 - Disponibilizado em: 30/11/2017

RESUMO: O café é uma das bebidas mais consumidas no mundo. Desde o século XIX, o consumo da bebida cresce apoiado por inovações tecnológicas. Uma dessas inovações consiste nas máquinas de café em dose única. No entanto, essa tecnologia causa danos ao meio ambiente devido aos materiais utilizados na fabricação das cápsulas, fato que preocupa ativistas, políticos e consumidores. Diante deste cenário, o presente artigo analisa as inovações sustentáveis que a indústria do café tem desenvolvido para lidar com o problema. Para isso, foram analisadas qualitativamente as estratégias de sete marcas de café em dose única. Os resultados mostraram que as empresas líderes do setor optaram pelo desenvolvimento de estratégias de reciclagem das cápsulas usadas. Por outro lado, apenas duas marcas possuem estratégias abrangentes de reciclagem. Os principais pontos fracos da reciclagem são a logística e dependência da iniciativa dos consumidores. Outra solução encontrada por marcas menores é a utilização de material compostável. Nesse caso, também há limitações, como a necessidade uma usina de compostagem.

PALAVRAS-CHAVE: Reciclagem. Cápsulas de café. Inovação Sustentável.

ABSTRACT: Coffee is one of the most consumed beverages in the world. Since the 19th century, technological innovations have boosted coffee consumption. The single cup coffee machines are one of these innovations. However, this technology causes damage to the environment due to the materials used in the coffee pods manufacture, an issue that worries activists, politicians and consumers. Given this scenario, the present article analyzes the sustainable innovations that the coffee industry has developed to deal with the problem. For this, the strategies of seven brands of single cup coffee were analyzed qualitatively. The results showed that leading companies in the sector opted for recycling strategies for used coffee pods. On the other hand, only two brands have comprehensive recycling strategies. The main weaknesses of recycling are logistics and dependence on consumer initiative. Another solution, found by smaller brands, is the use of compostable materials in single cups manufacture. In this case, there are also limitations, such as the need for a composting plant.

KEYWORDS: Recycling. Coffee pods. Sustainable innovation. 


\section{INTRODUÇÃO}

O café é uma das bebidas mais consumidas no mundo. Nos EUA e no Brasil, os dois maiores consumidores mundiais, perde apenas para a água (ABIC, 2015; NATIONAL COFFEE ASSOCIATION NCA, 2015). Segundo a International Coffee Organization $(2012,2015)$ o consumo mundial de café cresceu 66,1\% entre 1990 e 2014.

A indústria do café contou com inúmeras inovações a partir do século XIX que criaram novos métodos de preparo e ajudaram a popularizar a bebida (PENDERGRAST, 2010). Uma das mais recentes inovações foi a criação das máquinas de "café em dose única", que preparam uma xícara por vez com qualidade e praticidade (SANTOS; SILVA; CASTRO JUNIOR, 2012). A categoria "café em dose única" se refere tanto aos cafés acondicionados em cápsulas, que podem ser de plástico ou alumínio, quanto aos sachês, que consistem em pequenos discos de café torrado e moído compactados, envoltos por um filtro de papel.

Dados da Euromonitor (2016) mostram que em 2014 o valor das vendas de café em cápsulas já representava mais de $50 \%$ do total de café comercializado em Portugal, França e Holanda; mais de $40 \%$ das vendas na Suíça, Espanha e Canadá; e mais de 30\% no EUA. No Brasil, as vendas triplicaram entre 2010 e 2014 e chegaram a $3,6 \%$ do total.

Com o elevado crescimento das vendas de cápsulas no mundo todo, preocupações a respeito do lixo produzido com o seu descarte começaram a surgir. $\mathrm{O}$ plástico e o alumínio demoram muito para se decompore na natureza, por isto precisam ser reciclados para reduzir o impacto ambiental.

Em 2010, o The New York Times associou as cápsulas com a poluição (CARPENTER, 2010). Um relatório do Bureau de Inteligência Competitiva do Café, publicado em 2012, avaliou que a preocupação ambiental com o destino das cápsulas já era crescente naquele momento e haviam discussões sobre a proibição do comércio do produto (SANTOS; SILVA; CASTRO JUNIOR, 2012). As críticas se intensificaram nos anos seguintes e, em janeiro de 2015, uma organização civil norte-americana criou uma campanha contra a utilização da marca de cápsula mais popular da América do Norte.

A campanha publicou um vídeo no YouTube com o objetivo de atrair a atenção dos consumidores. Nele, um monstro, cujo corpo é formado por cápsulas, ataca uma cidade. A descrição do vídeo informa que o número de cápsulas comercializadas nos EUA em 2014 seria suficiente para circular o globo terrestre 10,5 vezes (KILL THE K-CUP, 2015).

Em março de 2015, o criador das K-Cups, modelo de cápsula mais vendido na América do Norte, John Sylvan, contou ao portal The Atlantic que se arrependia da sua invenção devido ao lixo que a tecnologia gerava (HAMBLIN, 2015). A declaração repercutiu na imprensa e foi citada por inúmeros portais de notícias. A preocupação ambiental com as cápsulas voltou a ganhar as manchetes em 2016, quando cidade alemã de Hamburgo proibiu a compra do produto nas repartições públicas municipais (BBC NEWS, 2016).

Diante desse cenário de crescente preocupação com o destino das cápsulas após o uso, é relevante estudar como as empresas do setor lidam com essa nova demanda da sociedade. Dessa maneira, o objetivo do trabalho foi identificar quais inovações sustentáveis as fabricantes de café em dose única estão desenvolvendo para reduzir o impacto ambiental gerado pelo produto, bem como as principais dificuldades enfrentadas por essas empresas no processo.

Para atender o objetivo, foram coletadas informações sobre as principais inovações sustentáveis desenvolvidas no segmento e, em seguida, dados 
sobre as estratégias empregadas pelas maiores fabricantes de cápsulas do mundo, de forma a analisar qualitativamente suas medidas sustentáveis. A coleta das informações foi por meio de pesquisa bibliográfica e documental.

\section{Referencial TeÓRICo}

Esta seção apresenta os principais conceitos teóricos que orientaram a condução do trabalho. Eles são discutidos em três subseções: desenvolvimento sustentável, inovação sustentável e adoção da inovação sustentável pelas empresas.

\subsection{DesenVolvimento SustentáVEL}

O aumento da conscientização sobre os problemas ambientais e da preocupação com o futuro do meio ambiente intensificaram-se a partir das transformações ocorridas na segunda metade do século $X X$, juntamente com os variados desastres ambientais registrados no período (VAN BELLEN, 2004).

De acordo com Hobsbawm (1995), a expansão do mundo industrial ocorrida no século $X X$, apesar de fomentar o crescimento da economia mundial, apresentava sinais ameaçadores para o ambiente, como a poluição e a deterioração ecológica. A partir de meados do século, intensificou-se o impacto na natureza causado pelas atividades exercidas pelo homem.

As reflexões críticas sobre a interferência da sociedade civil no meio ambiente influenciaram o debate internacional sobre desenvolvimento sustentável (VAN BELLEN, 2004). De acordo com Brüseke (1995), a década de 1970 foi marcada por discussões para a elaboração de um conceito alternativo de desenvolvimento que não envolvesse apenas o ideal de eficiência econômica, mas que abarcasse, também, os preceitos de justiça social e prudência ecológica. Entre as publicações apresentadas pelo autor, destacam-se 0 relatório Limites para o Crescimento, publicado em 1972; o surgimento do conceito sobre ecodesenvolvimento, em 1973 e a Declaração de Cocoyok, de 1974. Posteriormente, outros eventos contribuíram para a concepção de desenvolvimento sustentável, como a publicação do Relatório Brundtland, em 1987 e a Conferência da Organização das Nações Unidas sobre Meio Ambiente e Desenvolvimento, realizada em 1992, no Rio de Janeiro.

Os principais pontos levantados pelas discussões sobre desenvolvimento sustentável são as tendências de crescimento populacional, industrialização e a exploração dos recursos naturais e suas consequências (MEADOWS et al., 1972; BRUNTLAND, 1987); ponderações sobre o consumo excessivo e a pobreza (THE DECLARATION OF COCOYOC, 1975) e as preocupações com as gerações futuras, destacando a importância das necessidades humanas serem supridas no presente sem comprometer a capacidade das próximas gerações suprirem a suas (MEADOWS et al., 1972; BRUNTLAND, 1987; DECLARAÇÃO DO RIO DE JANEIRO, 1992).

Van Bellen (2004) ressalta que atualmente existem várias abordagens para explicar o conceito de desenvolvimento sustentável devido ao processo contínuo e complexo ao qual está submetido. Para Hopwood, Mellor e O’Brien (2005), esse conceito está relacionado aos problemas ambientais, socioeconômicos e as preocupações sobre um futuro saudável, além de representar uma mudança na compreensão da humanidade e sua posição no planeta.

Segundo Bora e Furlanetto (2015), os conceitos de desenvolvimento sustentável têm influenciado o cenário competitivo das organizações e as formas 
como seus produtos, processos e modelos de negócios são concebidos.

De acordo com Hall e Vredenburg (2003), nas últimas décadas, as empresas tornaram-se mais atentas às pressões sociais e ambientais sofridas. Os autores também argumentam que muitos estudiosos e consultores enxergam as novas demandas da sociedade como boas oportunidades para as organizações, que têm a inovação como um dos principais caminhos para o alcance do crescimento sustentável.

Para Moreira, Lima e Tótaro (2014), a sustentabilidade pode ser vista como um dos maiores desafios para a sociedade contemporânea, visto que 0 desenvolvimento econômico e social é necessário, porém deve-se respeitar o meio ambiente durante este processo.

\subsection{INOVAÇÃo SUSTENTÁVEL}

Schumpeter (1997) define inovação como uma mudança nos padrões estabelecidos, que compreende o aperfeiçoamento dos processos de produção, as substituições de um bem de produção ou consumo por outro, a criação de novos produtos, a busca por novos mercados e a criação de novas formas organizacionais.

A Organisation for Economic Co-operation and Development - OECD (2005) define inovação como as mudanças realizadas pelas empresas em seus métodos de trabalho e em seus fatores de produção, que melhoram a sua produtividade e desempenho. As empresas podem inovar em produtos, com a oferta de novos produtos/serviços ou no melhoramento dos já existentes; em processos, com a alteração nos métodos de produção e/ou entrega; as inovações podem ser organizacionais, que compreendem mudanças nas práticas de negócios, na organização do local de trabalho e/ou nas relações externas da empresa; e em marketing, com modificações no design do produto ou embalagem, na sua promoção e colocação no mercado, e em métodos para precificação dos bens ou serviços.

Kemp, Smith e Becher (2000) ressaltam que a inovação faz parte de um processo multinível de mudança, que envolve a organização, conhecimentos, crenças e vínculos entre os atores interdependentes e setores. Está relacionada a fazer algo qualitativamente novo ou diferente.

Muitas mudanças realizadas pelas organizações são impulsionadas pelas pressões da sociedade para o desenvolvimento sustentável (HALL; VREDENBURG, 2003). Diante disso, as organizações direcionam seu foco para atender as demandas sustentáveis a partir da união do bem-estar econômico, a equidade social e a proteção ao meio ambiente (KNEIPP et al., 2011). A inovação, portanto, não se limita apenas ao campo tecnológico, mas abrange também as áreas econômica, social, institucional e política. Perante esse novo cenário, as empresas se preocupam, cada vez mais, em inserir em seus processos meios para a avaliação dos seus impactos sociais, ambientais e econômicos. Isso se faz necessário para que as expectativas da opinião pública sejam atendidas e as organizações consigam preservar sua imagem e se manter no mercado (ALMEIDA, 2002).

A eco inovação ou inovação sustentável é um novo campo de inovações técnico-social voltado para o ambiente e para as pessoas (OECD, 2009). Consiste na modificação ou criação de novos processos, técnicas, práticas ou produtos no intuito de reduzir os danos ambientais (KEMP; SMITH; BECHER, 2000), na utilização eficiente e responsável dos recursos naturais (COMISSÃO EUROPEIA, 2013) e visa a prevenção e redução do risco ambiental, poluição e demais impactos negativos ao longo de todo seu ciclo de vida (COMISSÃO EUROPEIA, 2008 apud 
CARRILLO-HERMOSILLA; DEL RIO; KÖNNÖLÄ, 2010).

Segundo a OECD (2009), a inovação sustentável possui as mesmas características que os processos de inovação comuns, porém apresenta duas diferenças importantes: possui como resultado a diminuição nos impactos ambientais e, também, pode modificar as normas socioculturais existentes e estruturas institucionais.

A busca pelo desenvolvimento sustentável tem transformado o cenário competitivo e empresas inteligentes já começaram a adotar os preceitos da sustentabilidade como nova fronteira da inovação (NIDUMOLU; PRAHALAD; RANGASWAMI, 2009). As empresas que trabalham em prol do desenvolvimento sustentável, denominadas como ecoeficientes, são aquelas que conseguem minimizar a utilização de materiais e energia na concepção dos produtos e serviços, diminuir a dispersão de materiais tóxicos, aumentar a reciclabilidade dos materiais e a durabilidade dos seus produtos, além de maximizar o uso sustentável dos recursos renonáveis (BARBIERI, 2007).

Para Nidumolu, Prahalad e Rangaswami (2009), o processo de inovação sustentável também é estimulado pela preferência dos consumidores por opções "eco-friendly". Nesse caso, para conceber produtos que atendam às exigências dos consumidores, as organizações precisam compreender suas preocupações e examinar o ciclo de vida das peças produzidas.

O século XXI é marcado pelas reflexões acerca da produção e consumo em busca de melhorias nos impactos ambientais adversos. Dentre as reconsiderações, destacam-se a preocupação com as embalagens e a adoção do design para a sustentabilidade que abarcam ideias sobre embalagens retornáveis, embalagens reutilizáveis, embalagens fabricadas a partir de materiais recicláveis, embalagens produzidas com materiais biodegradáveis; refis, entre outras (ALBACH; RAZERA; ALVES, 2016).

\subsection{AdoçÃo dA INOVAÇÃo SUSTENTÁVEL PELAS EMPRESAS}

Segundo Küçükoğlu e Pinar (2015), a indústria se empenha para desenvolver novos produtos que apresentem um menor consumo de energia durante seu uso, o mínimo de resíduos após o descarte e a presença de nenhum material nocivo em sua composição, além de se atentar aos novos métodos de produção que utilizem menos materiais e menos energia durante o processo. Para os autores, essas ações geram benefícios tanto para o meio ambiente quanto para as indústrias.

Ramus (2002) observou em seu trabalho três tipos de iniciativas ambientais existentes. A primeira está relacionada a inovações que diminuem os impactos ambientais da empresa, como a redução e reciclagem dos resíduos; inovações voltadas para a resolução de um problema ambiental, como a diminuição de materiais nocivos; e as inovações que englobam o desenvolvimento de produtos ou serviços denominados como ecoeficientes, que utilizam menos recursos e energia.

Dangelico e Pujari (2010) investigaram 12 empresas, sediadas no Canadá e Itália, para compreender quais as motivações a inovação sustentável em produtos. Os resultados denotam a expectativa de crescimento de mercado, aumento nos lucros, melhoria na reputação e preocupação com a responsabilidade ambiental como fatores que influenciam a produção de produtos sustentáveis. Os autores também identificaram as principais inovações empregadas pelas empresas estudadas, dentre elas destaca-se a otimização das embalagens, com o uso de materiais recicláveis ou biodegradáveis, além da redução de 
materiais em sua produção. Para eles, a regulamentação das embalagens pode se tornar mais rigorosa no futuro.

Em relação ao setor alimentício, Bossle, Barcellos e Vieira (2016) analisaram os fatores internos e externos que contribuíram para a adoção da inovação sustentável por empresas de alimentos localizadas no Brasil. Entre os fatores internos, as autoras destacam - papel dos recursos humanos, seguido pela preocupação gerencial ambiental. Em relação aos fatores externos, os stakeholders foram apontados como principais agentes para a adoção de uma postura sustentável, em conjunto com as regulações ambientais e apoio governamental.

\section{Metodologia}

Trata-se de uma pesquisa de natureza qualitativa e propósito descritivo. As informações foram obtidas por meio de pesquisa bibliográfica e pesquisa documental. Enquanto a pesquisa bibliográfica utiliza materiais de domínio científico, proveniente de fontes como periódicos e livros, a pesquisa documental utiliza documentos ainda sem tratamento científico ou que podem ser reelaborados de acordo com os objetivos da pesquisa (GIL, 2002; OLIVEIRA, 2007).

A primeira etapa consistiu em uma pesquisa bibliográfica em 24 edições do Relatório Internacional de Tendências do Café (v.3 n.07 ao v.4 n.06). Trata-se de uma publicação mensal do Bureau de Inteligência Competitiva do Café que monitora as tendências da cadeia produtiva do café. $O$ objetivo foi identificar quais são as inovações sustentáveis mais utilizadas no segmento de café em dose única. A partir dessa análise inicial constatou-se que a indústria utiliza duas estratégias principais para mitigar o impacto ambiental das cápsulas: a) reciclagem das cápsulas usadas; e b) fabricação de cápsulas biodegradáveis.
$\mathrm{Na}$ segunda etapa, foi definida uma amostra de empresas para análise. O primeiro critério de seleção foi a participação de mercado. Segundo a consultoria Euromonitor (2016), as três companhias com maior Market share no mercado global em 2015 foram Nestlé (25,4\%), Keurig Green Mountain (14,7\%) e Jacobs Douwe Egberts (12,7\%). Como as três, juntas, são responsáveis por mais da metade das vendas mundiais da categoria, em valor, elas foram incluídas na amostra.

Nestlé e Jacobs Douwe Egberts atuam, cada uma, com duas marcas diferentes de café em dose única. Como cada marca possui características técnicas bastante distintas, como o material utilizado na fabricação, elas foram analisadas separadamente.

Após a análise preliminar dessas empresas, observouse que apenas uma marca utiliza material considerado biodegradável. Para aprofundar a análise dessa categoria, foram selecionadas mais duas companhias que fabricam cápsulas biodegradáveis. Uma é a canadense Coffee Club e a outra é a suíça Ethical Coffee Company. Dentre as fabricantes de cápsulas biodegradáveis, cada uma delas alega ter sido a pioneira em seu respectivo mercado geográfico. A Tabela 1 apresenta a relação das empresas que compuseram a amostra deste estudo e as marcas analisadas.

Tabela 1 - Relação das fabricantes de cápsulas analisadas

\begin{tabular}{cc}
\hline Empresa & Marcas \\
\hline Nestlé & $\begin{array}{c}\text { Nespresso; } \\
\text { Nescafé Dolce Gusto }\end{array}$ \\
\hline Keurig Green Mountain & Keurig Green Mountain \\
\hline Jacobs Douwe Egberts & Senseo; \\
& Tassimo \\
\hline Club Coffee & PurPod 100 \\
\hline
\end{tabular}

Fonte - Próprio autor. 
A terceira etapa consistiu na análise de fontes documentais relacionadas a cada empresa. As principais fontes utilizadas foram os relatórios de sustentabilidade (KEURIG GREEN MOUNTAIN, 2016a; NESTLÉ, 2016), web sites institucionais (COFFEE CLUB, 2016; ETHICAL COFFEE COMPANY, 2016; KEURIG GREEN MOUTAIN 2016b; JACOBS DOUWE EGBERTS, 2016; SENSEO, 2016) e, quando necessário, empresas parceiras (CLOSED LOOP FUND, 2016; RESOURCE RECYCLING SYSTEMS, 2016; SUSTAINABLE PACKAGING COALITION, 2016; TERRACYCLE, 2016a; TERRACYCLE, 2016b; TERRACYCLE, 2016c; KW PLASTICS, 2016).

Os materiais foram analisados em busca de informações sobre inovações adotadas para minimizar - impacto ambiental causado pelas cápsulas. O escopo do trabalho se limita à fabricação e destinação das cápsulas após o uso. Outras ações de cunho ecológico, como redução do consumo de energia nas fábricas e diminuição das emissões de carbono não foram estudadas.

\section{Resultados}

Esta seção apresenta os resultados da pesquisa, organizados para cada empresa individualmente.

\subsection{NestLé}

\subsubsection{NeSPRESSO}

A Nespresso é a marca líder nas vendas de café em dose única da Europa. Suas cápsulas são todas feitas de alumínio, um material que pode ser reciclado infinitamente (ALUMINIUM STEWARDSHIP INITIATIVE - ASI, 2016). Diante dessa característica do produto, ela adotou a reciclagem como estratégia de sustentabilidade.
Para viabilizar o processo, a Nespresso trabalha em parceria com outras organizações que ajudam na construção da logística de recolhimento do material descartado e na reciclagem. Os consumidores podem depositar as cápsulas usadas em milhares de pontos credenciados ao redor do mundo e nas lojas próprias da marca, as Boutique Nespresso, que eram mais de 270 em 2014.

A companhia estabeleceu três metas de sustentabilidade relacionadas com as cápsulas para 2020. A primeira é aumentar a capacidade de reciclagem para $100 \%$ de todas as cápsulas comercializadas em países onde ela atua oficialmente, além de elevar o percentual de cápsulas efetivamente recicladas. A segunda meta é utilizar o alumínio reciclado na fabricação de cápsulas novas; e a terceira consiste em obter $100 \%$ do alumínio virgem utilizado em acordo com o novo padrão da Aluminium Stewardship Initiative (ASI), uma organização criada em 2012 para promover a sustentabilidade e a transparência na indústria do alumínio (ASI, 2016).

\subsubsection{Nescafé Dolce Gusto}

Nescafé Dolce Gusto é uma linha de máquinas e café em cápsulas da Nestlé. Enquanto a Nespresso opera de maneira independente, pois é uma subsidiária, a Nescafé Dolce Gusto é controlada pela matriz, situação que chega a causar concorrência entre as duas marcas.

O relatório de sustentabilidade da Nestlé não apresenta informações sobre estratégias ou metas globais de reciclagem das cápsulas Dolce Gusto. A única informação apesentada é o início de um programa de reciclagem na Austrália e Nova Zelândia, desenvolvido em parceria com a TerraCycle, uma companhia especializada em reutilização de materiais descartados. Nesse programa, o consumidor deve secar as cápsulas, colocá-las em um saco plástico, 
imprimir uma etiqueta da TerraCycle e entregar em uma agência postal, sem custos. Para remessas acima de $2 \mathrm{~kg}$, a TerraCycle faz uma doação de U\$0,02 por cápsula para uma organização educacional ou de caridade escolhida pelo consumidor.

Em setembro de 2016, havia 414 agências postais participando do programa na Nova Zelândia e 210 na Austrália.

\subsection{KeURig Green Mountain}

A Keurig Green Mountain (KGM) é, atualmente, a empresa líder na venda de café em dose única na América do Norte. Após um grande crescimento nos últimos anos, foi adquirida pela JAB Holding em 2015. O seu relatório de sustentabilidade é, dentre as empresas analisadas, o que apresenta maior volume de informações sobre inovação sustentável.

As cápsulas da KGM, chamadas K-Cups, são feitas de plástico, com um filtro de papel e um lacre que fecha o recipiente. Segundo a companhia, o tipo de plástico utilizado nas cápsulas é aceito em metade das usinas de reciclagem dos EUA e Canadá, mas a companhia optou por pesquisar um novo material que pudesse ser aceito na maioria delas. A solução encontrada foi o polipropileno. As K-cups de polipropileno começaram a ser fabricadas em 2016 e a meta para 2020 é que toda a produção utilize o material.

O relatório da Keurig informa que o pequeno tamanho das cápsulas, a presença de borra de café após o preparo e de outros materiais, como o filtro de papel e o lacre, eram apontados como impedimentos à reciclagem. Em testes realizados pela empresa junto às usinas de reciclagem, K-Cups foram misturadas ao lixo comum para avaliar a taxa de recuperação. Os resultados mostraram que $70 \%$ delas foram separadas para reciclagem pelas máquinas das usinas, número considerado satisfatório. Além disso, os filtros de papel não atrapalharam o processo. No entanto, os recicladores preferem que a borra do café e o lacre sejam removidos pelo consumidor antes do descarte.

Um dos objetivos da Keurig é aumentar a taxa de recuperação das cápsulas. A empresa acredita que pequenas mudanças e padronizações nas máquinas das diferentes usinas de reciclagem poderão melhorar os resultados. Para isso, decidiu apoiar e investir no setor. Em 2014, juntou-se ao Closed Loop Fund, fundo de impacto social que possui como objetivo o investimento de US $\$ 100$ milhões para o aumento da reciclagem de produtos e embalagens. A empresa pretende investir US\$5 milhões nesse fundo, no período de 5 anos, para apoiar o desenvolvimento da infraestrutura de reciclagem.

A KGM participa da The Association of Plastic Recyclers, uma associação constituída por recicladores de plásticos e proprietários de marcas, que buscam o desenvolvimento de soluções para a reciclagem do material. Também é membro da Sustainable Packaging Coalition, grupo de trabalho da indústria com foco no desenvolvimento de embalagens produzidas com materiais sustentáveis.

Em 2015, a empresa trabalhou em conjunto com a Resource Recycling Systems (RRS), empresa de consultoria em sustentabilidade, e a KW Plastics, especializada em reciclagem, para avaliar o desempenho das cápsulas no processo de reciclagem.

\subsection{Jacobs DouWe EgBerts}

\subsubsection{SENSEO}

Senseo é a principal marca de café em dose única da Jacobs Douwe Egberts (JDE). A JDE é uma empresa nova, formada a partir da aquisição de companhias tradicionais e importantes da indústria do café pela JAB Holding. O café Senseo não é acondicionado dentro de cápsulas de plástico ou alumínio, mas em 
um filtro de papel. Segundo Carpenter (2010), o filtro é totalmente biodegradável, o que torna desnecessário a criação de ações específicas para a sustentabilidade.

Entretanto, o web site do produto, em sua versão para - mercado do Reino Unido, não apresenta informações específicas sobre a biodegradação do filtro. Há apenas uma menção ao fato dos sachês serem uma das opções mais ecologicamente amigáveis de café em dose única. $A$ empresa não publica relatórios anuais de sustentabilidade.

\subsubsection{TASSIMO}

Tassimo é a segunda maior marca de café em dose única da Jacobs Douwe Egberts. O café é acondicionado em cápsulas de plástico chamadas Tdiscs que são compatíveis apenas com as máquinas da marca. No Reino Unido, as T-discs podem ser enviadas para reciclagem por meio de uma parceria entre a Tassimo e a TerraCycle. As T-discs usadas devem ser depositadas em um dos 268 pontos de coleta credenciados e, depois, são transformadas em novos produtos plásticos. A fabricante não apresenta informações sobre parcerias deste tipo em outros países.

\subsection{Coffee Club}

Em 2015, a companhia canadense Coffee Club lançou, uma cápsula compostável, ou seja, que se degrada em matéria orgânica se houver condições adequadas de calor e umidade. A tecnologia foi batizada de PurPod 100 e as cápsulas são compatíveis com as máquinas da KGM. A empresa fabrica as cápsulas biodegradáveis para marcas de café dos Estados Unidos e Canadá.

A tecnologia PurPod 100 é anunciada como "certificada $100 \%$ compostável". A certificação foi concedida pelo Biodegradable Products Institute (BPI), uma associação profissional independente composta por membros do governo, indústria e academia para a promoção do uso de polímeros biodegradáveis (BPI, 2016). A BPI testa sacolas, embalagens e outros objetos em laboratórios independentes de acordo com normas estabelecidas pela ASTM International. Os produtos aprovados podem utilizar o selo da BPI, que é reconhecido nos EUA e no Canadá como padrão para compostagem.

O selo indica que as cápsulas são compostáveis apenas em usinas específicas para este fim. Para que o processo seja efetivo e ocorra dentro do prazo estipulado é preciso um ambiente controlado. A empresa explica que isso diferencia o compostável do "biodegradável", sendo este um produto que pode se decompor junto ao lixo comum. Além disso, a biodegradação pode levar anos se as condições não forem as ideais. Por isso, o selo BPI destaca que as cápsulas não são certificadas para compostagem doméstica. O certificado pode ser validado por meio do seu número no web site da BPI (www.bpiworld.org). A PurPod 100 foi a primeira cápsula certificada pela BPI.

\subsection{Ethical Coffee Company}

A Ethical Coffee Company (ECC) foi fundada em 2008 por Jean-Paul Gaillard, um ex-diretor da Nespresso. A empresa possui sede na suíça e uma fábrica de cápsulas na França. Ela produz cápsulas compatíveis com as máquinas Nespresso que são biodegradáveis de acordo com a norma EN 13432 da União Europeia.

Segundo a ECC, as cápsulas são 100\% feitas de fibras vegetais que se degradam no prazo de 6 meses. Assim como a PurPod 100, o processo precisa ocorrer dentro de uma usina de compostagem. 


\section{Análise dos Resultados}

A análise das informações disponibilizadas pelas marcas selecionadas permitiu a identificação de alguns pontos importantes sobre a inovação sustentável do mercado de café em dose única. Dentre as 5 marcas mais vendidas no mundo em 2015, três utilizam cápsulas de plástico, uma usa cápsulas alumínio e uma utiliza sachê de filtro de papel. Como o papel é biodegradável, esta é a opção mais ecológica dentre as analisadas neste estudo. Os demais materiais necessitam passar por um processo de reciclagem, o que influenciou a estratégia de inovação sustentável das outras marcas.

De acordo com Moreira, Lima e Tótaro (2014), o maior objetivo da reciclagem é a preservação do meio ambiente. Por meio dela, diminui-se a poluição do solo, da água e do ar. Segundo Silva et al. (2011), o conceito de reciclagem pode ser aplicado apenas aos materiais que após o processo conseguem voltar ao estado original e serem transformados, mais uma vez, em um produto com todas as características iguais.

Das quatro marcas que utilizam cápsulas, duas possuem metas definidas para redução dos danos ambientais causados pelo descarte do produto. $O$ alumínio das cápsulas Nespresso é naturalmente reciclável, por isso, a empresa concentra seus esforços na ampliação da "capacidade de reciclagem", com o intuito de que toda a produção possa ser reaproveitada. Por sua vez, a Keurig precisou investir em pesquisa e inovação para desenvolver suas KCups a partir de polipropileno.

No entanto, a estratégia das duas marcas não garante que todas as cápsulas serão efetivamente recicladas. Em ambos os casos a reciclagem depende da colaboração dos consumidores, responsáveis por enviar o lixo produzido para os locais capazes de processar o material. Nesse aspecto, a consciência ambiental dos indivíduos e o acesso a pontos de coleta próximos ao trabalho/residência podem limitar a taxa de reciclagem. Como Gunther (2015) notou, a Nespresso não divulga o percentual de cápsulas efetivamente recicladas. Eventualmente, a Keurig Green Mountain enfrentará o mesmo tipo problema, já que as cápsulas deverão chegar até as usinas com capacidade para processar o polipropileno.

Por sua vez, Tassimo e Nescafé Dolce Gusto apresentam apenas ações restritas de reciclagem. Silva et al. (2015) observaram que Nespresso e Keurig Green Mountain são empresas totalmente especializadas na fabricação de cápsulas, enquanto Nescafé Dolce Gusto e Tassimo fazem parte de um portfólio maior de produtos das multinacionais Nestlé e Jacobs Douwe Egberts, o que poderia explicar o maior engajamento daquelas na reciclagem.

Uma inovação adotada por companhias de menor porte são as cápsulas compostáveis. A compostagem, de acordo com Kale, Auras e Singh (2006), consiste em um processo natural no qual o material orgânico é decomposto em húmus. A decomposição é realizada, principalmente, por microorganismos, porém as minhocas, pequenos insetos e demais organismos que habitam o solo contribuem para a compostagem em temperaturas mais baixas. Os principais grupos de microorganismos envolvidos nesse processo são as bactérias, fungos e actinomicetos. Eles decompõem a matéria orgânica como sua fonte de alimento.

A análise de duas empresas que trabalham com essa tecnologia mostra que tanto na Europa quanto nos EUA existem normas a serem seguidas para que um produto seja certificado como compostável. No entanto, nesse caso também existem restrições. As duas certificações identificadas no estudo são válidas apenas para compostagem em usinas, o que causa o mesmo tipo de limitação observado no caso da reciclagem, ou seja, a destinação correta das cápsulas usadas depende da conscientização dos consumidores. 
A Tabela 2 apresenta o material utilizado por cada

compostagem e as inovações adotadas.

marca, suas características quanto a reciclagem ou

Tabela 2 - Inovações sustentáveis de produto e processo adotadas pelas empresas

\begin{tabular}{|c|c|c|}
\hline Marca & Inovação Sustentável de Produto & Inovação Sustentável de Processo \\
\hline Nespresso & $\begin{array}{l}\text { Utilização de material reciclável } \\
\text { (alumínio) desde o início. }\end{array}$ & $\begin{array}{l}\text { Parcerias com outras organizações para } \\
\text { coleta e transporte das cápsulas; } \\
\text { reaproveitamento do alumínio para } \\
\text { fabricação de novas cápsulas; aquisição } \\
\text { de alumínio produzido em acordo com as } \\
\text { normas da ASI; até } 2020 \text { a empresa terá } \\
\text { capacidade para reciclar } 100 \% \text { das } \\
\text { cápsulas fabricadas. }\end{array}$ \\
\hline Nescafé Dolce Gusto & Nenhuma & $\begin{array}{l}\text { Parceria com a Terra Cycle para coleta e } \\
\text { reciclagem das cápsulas na Austrália e } \\
\text { Nova Zelândia. }\end{array}$ \\
\hline Senseo & $\begin{array}{l}\text { Utilização de material biodegravável } \\
\text { (filtro de papel) desde o início. }\end{array}$ & Nenhuma \\
\hline Tassimo & Nenhuma & $\begin{array}{l}\text { Parceria com a Terra Cycle para coleta e } \\
\text { reciclagem das cápsulas no Reino Unido. }\end{array}$ \\
\hline Keurig Green Mountain & $\begin{array}{l}\text { Cápsulas de polipropileno a partir de } \\
2016 ; 100 \% \text { das cápsulas serão de } \\
\text { polipropileno até } 2020 \text {. }\end{array}$ & $\begin{array}{l}\text { Parceria com outras organizações para } \\
\text { adaptar as usinas de reciclagem dos EUA } \\
\text { e Canadá. }\end{array}$ \\
\hline PurPod 100 & $\begin{array}{l}\text { Cápsulas compostáveis em usinas } \\
\text { específicas, de acordo com } \\
\text { certificação BPI. }\end{array}$ & Nenhuma \\
\hline Ethical Coffee & $\begin{array}{l}\text { Cápsulas compostáveis em usinas } \\
\text { específicas, de acordo com a norma } \\
\text { EN } 13432 .\end{array}$ & Nenhuma \\
\hline
\end{tabular}

Fonte - Próprio autor.

É importante destacar que Nespresso e Keurig direcionam seus esforços no sentido de criar condições de reciclagem para as suas cápsulas, no entanto, sem garantir que elas sejam realmente recicladas. Isso ocorre porque o consumidor é um ator importante dentro do processo. É ele quem deve levar as cápsulas usadas até os pontos de coleta. Se o consumidor não fizer isso, o problema persistirá.

Outra limitação dos modelos analisados é a falta de dados sobre o percentual de single cups que cada companhia recicla. A Nespresso alega que a informação é confidencial (CUNHA, 2016), enquanto as demais não fornecem informações quanto a isso. No modelo adotado pela KGM, é provável que seja impossível determinar os percentuais de reciclagem, já que o processo ocorrerá em usinas que não possuem ligação com a empresa.

Ainda assim, são as duas marcas mais adiantadas em inovações sustentáveis para a reciclagem de cápsulas. Nescafé Dolce Gusto e Tassim estão em estágios iniciais.

\section{Considerações Finais}

Este trabalho permitiu identificar aspectos importantes da inovação sustentável no mercado de café em dose única. Diante da pressão da sociedade, as companhias do setor investem em soluções mais ecológicas, mas ainda há pontos fracos no processo. A reciclagem mostra-se como a estratégia preferida 
pelas grandes companhias, 0 que requer investimentos em logística e pesquisa de novos materiais. Além disso, o grande desafio para o futuro será a elevação da taxa real de cápsulas recicladas, algo que é dificultado por características inerentes ao processo.

As cápsulas compostáveis também possuem limitações. As certificações utilizadas nos dois casos avaliados são válidas apenas para a compostagem em usinas próprias. Em meio às marcas analisadas, os sachês Senseo revestidos por um filtro de papel aparentam ser uma solução ecológica, mas não foram encontradas informações detalhadas sobre isso.

A principal limitação do estudo é a utilização apenas de informações secundárias, obtidas por pesquisa documental. No entanto, a partir dos resultados obtidos, outras pesquisas poderão explorar novos aspectos da inovação sustentável no mercado de café em dose única. Estudos futuros poderão abordar, entre outras questões, a percepção dos consumidores quanto à reciclagem e compostagem das cápsulas, fatores determinantes da colaboração do consumidor nestes processos; possíveis diferenças na qualidade da bebida decorrentes dos materiais utilizados e estratégias de comunicação utilizadas pelas empresas para conscientizar os consumidores.

\section{AgradeCIMENTOS}

Os autores agradecem ao Conselho Nacional de Desenvolvimento Científico e Tecnológico (CNPQ).

\section{REFERÊNCIAS}

ABIC - ASSOCIAÇÃO BRASILEIRA DAS INDÚSTRIAS DO CAFÉ. Indicadores da Indústria 2014. 2015. Disponível em < http://abic.com.br/estatisticas/indicadores-daindustria/indicadores-da-industria-2014/>. Acesso em 11 set. 2016

ALBACH, D.; RAZERA, D.; ALVES, J. L. Design para a sustentabilidade e a relação histórica das embalagens com questões ambientais. MIX

Sustentável, v. 2, n. 1, p. 45-52, 2016. Disponível em <http://ojs.sites.ufsc.br/index.php/mixsustentavel/articl e/view/1295>. Acesso em: 15 set. 2016. ISSN 24473073.

ALMEIDA, F. O bom negócio da sustentabilidade. 1. ed. Rio de Janeiro: Nova Fronteira, 2002. 191 p. ISBN 85-209-1266-4.

ALUMINIUM STEWARDSHIP INITIATIVE. ASI's objectives. 2016. Disponível em <http://aluminiumstewardship.org/about-asi/ >. Acesso em 12 set. 2016.

BARBIERI, J. C. Gestão ambiental empresarial: conceitos, modelos e instrumentos. 2. ed. São Paulo: Saraiva, 2007. 382 p. ISBN 978-85-02-05952-8.

BBC NEWS. Is there a problem with coffee capsules? BBC News, 19 fev. 2016. Disponível em <http://www.bbc.com/news/magazine-35605927>. Acesso em 12 set. 2016.

BORA, S. M.; FURLANETTO, E. L. Determinantes das inovações sustentáveis na base da pirâmide: um estudo em organizações brasileiras. In: XVII ENGEMA, 2015, São Paulo. Anais do XVII ENGEMA. 2015. São Paulo: Universidade de São Paulo, 2015. p. 1-15. Disponível em < http://engemausp.submissao.com.br/17/anais/resumo. php?cod_trabalho=401>. Acesso em 13 set. 2016.

BOSSLE, M. B.; BARCELLOS, M. D.; VIEIRA, L. M. Why food companies go green? The determinant factors to adopt eco-innovations. British Food Journal, v. 118, n. 6, p. 1317-1333, 2016. Disponível em

<http://www.emeraldinsight.com/doi/abs/10.1108/BFJ10-2015-0388? af=R\&>. Acesso em 12 set. 2016. ISSN 0007-070X.

BPI - BIODEGRADABLE PRODUCTS INSTITUTE. The Compostable Logo. Nova York: Biodegradable Products Institute, 2016. Disponível em <http://www.bpiworld.org/BPI-Public/Program.html>. Acesso em 12 set. 2016.

BRUNTLAND, G. H. (editor). Our Common Future: The World Commission on Enviroment and 
Development. Oxford: Oxford University Press, 1987. Disponível em < http://www.un-documents.net/ourcommon-future.pdf>. Acesso em 10 set. 2016.

BRÜSEKE, F. J. O problema do desenvolvimento sustentável. In: CAVALCANTI, C. Desenvolvimento e natureza: estudos para uma sociedade sustentável. São Paulo: Cortez, 1995. Disponível em <https://www.researchgate.net/profile/Andri_Stahel/pu blication/242508694_DESENVOLVIMENTO_E_NATU REZA_Estudos_para_uma_sociedade_sustentavel/lin ks/02e7e52dec936ba1f7000000.pdf>. Acesso em 12 set. 2016. ISBN 85-249-0572-7.

CARPENTER, M. A Coffee Conundrum. The New York Times, 03 ago. 2010. Disponível em <http://www.nytimes.com/2010/08/04/business/energyenvironment/04coffee.html?_r=0>. Acesso em 12 set. 2016.

CARRILLO-HERMOSILLA, J.; DEL RÍO, P.; KÖNNÖLÄ, T. Diversity of eco-innovations: Reflections from selected case studies. Journal of Cleaner Production, v. 18, n. 10, p. 1073-1083, jul. 2010. Disponível em

<http://www.sciencedirect.com/science/article/pii/S095 $0959652610000>$. Acesso em 11 set. 2016. ISSN 0959-6526.

COFFEE CLUB. PurPod100. 2016. Disponível em < http://purpod100.com/>. Acesso em 12 set. 2016.

\section{CLOSED LOOP FUND. About CLF. Closed Loop} Fund, 2016. Disponível em

<http://www.closedloopfund.com/about/>. Acesso em 13 set. 2016.

\section{COMISSÃO EUROPEIA. Cip eco-innovation first} application and market replication projects. 2013. Disponível em < http://ec.europa.eu/environment/ecoinnovation/files/docs/faq/faq-call-2013.pdf>. Acesso em 15 set. 2016.

CUNHA, J. Febre das cápsulas de café não é acompanhada pela reciclagem. Folha de S. Paulo, 24 jan. 2016. Disponível em

<http://www1.folha.uol.com.br/mercado/2016/01/17328 54-febre-das-capsulas-de-cafe-nao-e-acompanhadapela-reciclagem.shtml>. Acesso em 12 set. 2016.

DANGELICO, R. M.; PUJARI, D. Mainstreaming green product innovation: why and how companies integrate environmental sustainability. Journal of Business Ethics, v. 95, n. 3, p. 471-486, set. 2010. Disponível em

<https://www.researchgate.net/publication/226381764 _Mainstreaming_Green_Product_Innovation_Why_an d_How_Companies_Integrate_Environmental_Sustain ability>. Acesso em 15 set. 2016. ISSN 0167-4544.
DECLARAÇÃO DO RIO DE JANEIRO. Estudos avançados, São Paulo, v. 6, n. 15, ago. 1992, p. 153159. Disponível em

$<$ http://www.scielo.br/scielo.php?script=sci_arttext\&pid $=$ S0103-40141992000200013\&lng=en\&nrm=iso $>$.

Acesso em 15 set. 2016. ISSN 1806-9592.

ETHICAL COFFEE COMPANY. Biodegrability. Ethical Cooffee Company, 2016. Disponível em <http://www.ethicalcoffeecompany.com/en/biodegrada bility>. Acesso em 12 set. 2016.

\section{EUROMONITOR. Coffee Market Share by}

Company. Euromonitor, 2016. Disponível em < http://www.euromonitor.com/> (assinatura). Acesso em 11 set. 2016.

GIL, A. C. Como elaborar projetos de pesquisa. 4. ed. São Paulo: Atlas, 2002. 175 p. ISBN 85-224-31698.

GUNTHER, M. The good, the bad and the ugly: sustainability at Nespresso. The Guardian, 27 maio 2015. Disponível em $<$ https://www.theguardian.com/sustainablebusiness/2015/may/27/nespresso-sustainabilitytransparency-recycling-coffee-pods-values-aluminum>. Acesso em 12 set. 2016.

HALL, J.; VREDENBURG, $\mathrm{H}$. The challenges of innovating for sustainable development. Mit Sloan Management Review, v. 45, n. 1, p. 61-68, out. 2003. Disponível em <http://sloanreview.mit.edu/article/thechallenges-of-innovating-for-sustainabledevelopment/>. Acesso em 13 set. 2016. ISSN 15329194.

HAMBLIN, J. A Brewing Problem. The Atlantic, 2 mar. 2015. Disponível em $<$ http://www.theatlantic.com/technology/archive/2015/0 3/the-abominable-k-cup-coffee-pod-environmentproblem/386501/>. Acesso em 12 set. 2016.

HOBSBAWM, E. A Era dos Extremos: O breve século 1914 - 1991. 2ํe edição. São Paulo: Companhia das Letras, 1995. 632 p. ISBN 5-7164-468-3

HOPWOOD, B.; MELLOR, M.; O'BRIEN, G. Sustainable development: mapping different approaches. Sustainable Development, v.13, n. 1, p. 38-52, fev. 2005. Disponível em < https://www.researchgate.net/publication/227650585 Sustainable_Development_Mapping_Different_Approa ches>. Acesso em 11 de set. 2016. ISSN 1099-1719.

INTERNATIONAL COFFEE ORGANIZATION. Monthly Coffee Market Report: May 2012. 2012. Disponível em <http://www.ico.org/documents/cmr0512-e.pdf>. Acesso em 29 ago. 2016. 
INTERNATIONAL COFFEE ORGANIZATION. Coffee Market Report: July 2015. 2015. Disponível em <http://www.ico.org/documents/cy2014-15/cmr-0715e.pdf >. Acesso em 29 ago. 2016.

\section{JACOBS DOUWE EGBERTS. Corporate}

Responsibility. 2016. Disponível em < https://www.jacobsdouweegberts.com/CR/>. Acesso em 10 set. 2016.

KALE, G.; AURAS, R.; SINGH, S. P. Degradation of commercial biodegradable packages under real composting and ambient exposure conditions. Journal of Polymers and the Environment, v. 14, n. 3, p. 317-334, jul. 2006. Disponível em <http://link.springer.com/article/10.1007/s10924-0060015-6>. Acesso em 01 set. 2016. ISSN 1572-8900.

KEMP, R.; SMITH, K.; BECHER, G. How should we study the relationship between environmental regulation and innovation? In: European Commission JRC-IPTS and Enterprise DG. The impact of EU regulation on innovation of European Industry. 2000. Disponível em <http://ftp.jrc.es/EURdoc/eur19827en.pdf>. Acesso em 14 set. 2016.

KEURIG GREEN MOUTAIN. Sustainability Report: Fisca Year 2015. 2016a. Disponível em < http://www.keuriggreenmountain.com/ /media/Sustain ability/PDF/ReportsDisclosures/KeurigSustainabilityRe port_2015.ashx>. Acesso em 10 set. 2016.

KEURIG GREEN MOUNTAIN. Sustainability. 2016b. Disponível em <

http://www.keuriggreenmountain.com/en/Sustainability/ Overview.aspx>. Acesso em 10 set. 2016.

KILL THE K-CUP. 2015. Disponível em <https://www.youtube.com/watch?v=uRGiGbX9llo>. Acesso em 10 set. 2016.

KNEIPP, J. M. et al. Emergência temática da inovação sustentável: uma análise da produção científica através da base web of science. Revista de Administração da UFSM, v. 4, n. 3, p. 442-457, set/dez. 2011. Disponível em

<https://periodicos.ufsm.br/reaufsm/article/view/3755/2 606>. Acesso em 10 set. 2016. ISSN 1983-4659.

KÜÇÜKOĞLU, M. T.; PINAR, R. I. Positive Influences of Green Innovation on Company Performance.

Procedia-Social and Behavioral Sciences, v. 195, p. 1232-1237, jul. 2015. Disponível em

<http://www.sciencedirect.com/science/article/pii/S187 7042815037404>. Acesso em 10 set. 2016. ISSN 1877-0428.
KW PLASTICS. About us. KW Plastics, 2016. Disponível em < http://www.kwplastics.com/aboutus/>. Acesso em 13 set. 2016.

MEADOWS, D. H. et al.. The Limits to Growth. New York: Universe Books, 1972. 205 p. ISBN 0-87663165-0.

MOREIRA, J. L.; LIMA, L. G. R.; TÓTARO, L. S. Empreendedorismo sustentável: o valor de negócios ambientais. Revista e-xacta, v. 6, n. 2, p. 177-189, 2014. Disponível em < http://revistas.unibh.br/index.php/dcet/article/view/1083 /628>. Acesso em 10 set. 2016. ISSN 1984-3151

NATIONAL COFFEE ASSOCIATION. Coffee is americans' favored daily beverage next to water. National Coffee Association, 2015. Disponível em <http://www.ncausa.org/i4a/pages/index.cfm?pagelD= 1062>. Acesso em 29 ago. 2016.

\section{NESTLÉ. Nestlé in Society Creating Shared Value} and meeting our commitments 2015. 2016. Disponível em < http://www.nestle.com/assetlibrary/documents/ibrary/documents/corporate_social_ responsibility/nestle-csv-full-report-2015-en.pdf $>$. Acesso em 10 set. 2016.

NIDUMOLU, R., PRAHALAD, C. K., RANGASWAMI, M. R. Why Sustainability Is Now the Key Driver of Innovation. Havard Business Review, v. 87, n. 9, p. 27-34, set. 2009. Disponível em < https://hbr.org/2009/09/why-sustainability-is-now-thekey-driver-of-innovation>. Acesso em 10 set. 2016. ISSN 0017-8012.

OLIVEIRA, M. M. Como fazer pesquisa qualitativa. 2. ed. Petrópolis: Vozes, 2007. 192 p. ISBN 9788532633774

ORGANISATION FOR ECONOMIC CO-OPERATION AND DEVELOPMENT (OECD). Manual Oslo: guidelines for collecting and interpreting innovation data. $3^{\circ}$ edição. Paris: OECD Publishing, 2005. Disponível em <http://www.oecd-

ilibrary.org/docserver/download/9205111e.pdf?expires $=1474061740 \& i d=i d \& a c c n a m e=$ guest $\&$ checksum $=3 D 0$ A9B4345A6D9A56267834D99C0060A >. Acesso em: 14 set. 2016.

ORGANISATION FOR ECONOMIC CO-OPERATION AND DEVELOPMENT (OECD). Sustainable Manufacturing and Eco-innovation: Towards a Green Economy. Paris: Policy Brief, 2009. Disponível em <https://www.oecd.org/env/consumptioninnovation/42957785.pdf>. Acesso em 14 set. 2016.

PENDERGRAST, M. Uncommon Grounds: The History of Coffee and How it Transformed our World. 
New York: Basic Books, 2010. 480 p. ISBN 978-0-46501836-9.

RAMUS, C. A. Encouraging innovative environmental actions: what companies and managers must do. Journal of world business, v. 37, n. 2, p. 151-164, 2002. Disponível em <http://www.sciencedirect.com/science/article/pii/S109 $0951602000743>$. Acesso em 11 set. 2016. ISSN 1090-9516.

RESOURCE RECYCLING SYSTEMS. About us. Resource Recycling Systems, 2016. Disponível em $<$ http://recycle.com/about-us/>. Acesso em 13 set. 2016.

SANTOS, P. H. A.; SILVA, E. C.; CASTRO JUNIOR, L. G. Introdução ao mercado de café em dose única e perspectivas para o Brasil, 2012. Disponível em

<http://www.icafebr.com.br/publicacao2/Introducao\%2 0ao\%20Mercado\%20de\%20Cafe\%20em\%20Dose\%2 0\%C3\%9Anica\%20e\%20Persperctivas\%20para\%20o \%20Brasil.pdf>. Acesso em 12 set. 2016.

SILVA, E. C. et al. Governança privada e sustentabilidade na indústria do café. In: XVII ENGEMA, 2015, São Paulo. Anais do XVII ENGEMA. 2015. São Paulo: Universidade de São Paulo, 2015. Disponível em <http://engemausp.submissao.com.br/17/anais/arquivo s/138.pdf>. Acesso em 14 set. 2016.

SILVA, F. E. N. et al. Azulejaria sustentável. Revista e-xacta, v. 4, n. 2, p. 97-102, 2011. Disponível em $<$ http://revistas.unibh.br/index.php/dcet/article/view/347 $/ 180$ >. Acesso em 10 set. 2016. ISSN 1984-3151

SCHUMPETER, J. A. Teoria do Desenvolvimento

Econômico: uma investigação sobre lucros, capital, crédito, juros e o ciclo econômico. São Paulo: Nova Cultural, 1997. 237 p. ISBN 85-351-0915-3.
SUSTAINABLE PACKAGING COALITION. Who we are. Sustainable Packaging Coalition, 2016.

Disponível em

$<$ http://www.sustainablepackaging.org/>. Acesso em 13 set. 2016.

TERRACYCLE. The Tassimo Recycling

Programme. Terracycle, 2016a. Disponível em $<$ http://www.terracycle.co.uk/en-UK/brigades/thetassimo-brigade-r>. Acesso em 12 set. 2016.

TERRACYCLE. Nescafé Dolce Gusto Capsule Recycling Program. Terracycle, 2016b. Disponível em <http://www.terracycle.com.au/en-

AU/brigades/capsulebrigade $>$. Acesso em 12 set. 2016.

\section{TERRACYCLE. Nescafé Dolce Gusto Capsule}

Recycling Programme. Terracycle, 2016c. Disponível em <http://www.terracycle.co.nz/en-

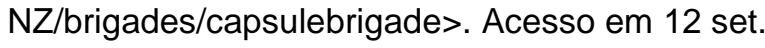
2016.

THE DECLARATION OF COCOYOC. World

Development, v. 3, n. 2-3, fev/mar. 1975, p. 141-148.

Disponível em <

http://www.sciencedirect.com/science/article/pii/03057 50X75900443>. Acesso em 13 set. 2016. ISSN 0305$750 \mathrm{X}$

VAN BELLEN, H. M. Indicadores de sustentabilidade: um levantamento dos principais sistemas de avaliação. Cadernos EBAPE.BR, n.1, v. II, mar. 2004. Disponível em

<http://www.scielo.br/pdf/cebape/v2n1/v2n1a02.pdf>. Acesso em 14 set. 2016. ISSN 1679-3951. 